\title{
Políticas morales e ideas: el porte de cannabis para uso personal en Chile (1973-2015)
}

\author{
Moral policies and ideas: the possession of cannabis for personal use in Chile \\ (1973-2015)
}

\author{
VIRgINIA LABIANO ${ }^{1}$ \\ Universidad Nacional de San Martín/CONICET, Argentina
}

\begin{abstract}
RESUMEN En el presente artículo hacemos una descripción de la política de drogas en Chile en relación al porte de sustancias ilícitas para consumo personal, específicamente de cannabis. Para ello articulamos la teoría ideacional -a través de una propuesta conceptual, el esquema cognitivo-normativo que predomina en la dirigencia política- con la perspectiva de las políticas públicas morales. El objetivo es mostrar cómo el esquema cognitivo-normativo que se formó en la dirigencia chilena en los '70 cuando el problema de las drogas entra en la agenda legislativa ha perdurado a lo largo del desarrollo de la política de drogas. Examinamos los procesos que dieron como resultado las leyes 17.934 de 1973 , la 18.403 dictada en 1985 así como la ley 19.366 de 1995 y la 20.000 promulgada en 2005. Finalmente analizamos el intento por regular el porte y el autocultivo de cannabis durante 2014-2015.
\end{abstract}

PALABRAS CLAVE Chile; políticas morales; ideas; porte personal; cannabis.

ABSTRACT In this article we describe drug policy in Chile in relation to the possession of illicit substances for personal consumption, specifically cannabis. To do so, we articulate ideational theory - through a conceptual proposal, the cognitive-normative scheme that predominates in the country's political leadership - with the perspective of moral policies. The objective is to show how the cognitive-normative scheme that was formed in the Chilean leadership in

1. Candidata a doctora en Ciencia Política por la Universidad Nacional de San Martín; se desempeña como becaria doctoral Conicet. E-mail: vlabiano@unsam.edu.ar. (iD) https://orcid.org/00000003-3089-7173?lang=es 
the 1970s, when the drug problem entered the legislative agenda, has endured throughout the evolution of drug policy. We examine the processes that resulted in laws 17.934 of 1973, 18.403 dictated in 1985, 19.366 of 1995 and 20.000 promulgated in 2005. Finally, we analyze the attempt to regulate the possession and personal cultivation of cannabis during 2014-2015.

KEYWORDS Chile; moral policies; ideas; personal possession; cannabis.

\section{Introducción}

En el presente artículo hacemos una descripción de la política de drogas en Chile en relación al porte de sustancias ilícitas para consumo personal, específicamente de cannabis. Para ello articulamos la teoría ideacional -a través de una propuesta conceptual, el esquema cognitivo-normativo que predomina en la dirigencia políticacon la perspectiva de las políticas públicas morales. El objetivo es mostrar cómo el esquema cognitivo-normativo que se formó en la dirigencia chilena en los '7o, cuando el problema de las drogas entra en la agenda legislativa, ha perdurado a lo largo del desarrollo de la política de drogas².

De esta esta manera, en las secciones iniciales exponemos el marco teórico desde el cual se hará la descripción de la política. En el primer apartado presentamos las políticas morales -es decir, aquellas políticas que refieren a valores sociales más que a intereses económicos, tales como el aborto, la eutanasia, matrimonio entre personas no heterosexuales, la utilización de células embrionarias, etc. A continuación, hacemos una aproximación a la explicación ideacional de los fenómenos sociales y en ese marco teórico desarrollamos el esquema cognitivo-normativo como la articulación de ideas y valores que delinean las relaciones de causa-efecto que orientan a los decisores y que residen en el trasfondo de los debates. Particularmente, este esquema se organiza en torno a tres componentes presentes en las políticas morales: la concepción del ciudadano, la consideración sobre la conducta, y la responsabilidad del Estado ante el fenómeno. Con estas herramientas teóricas abordamos la sociohistoria

2. Este artículo deriva de mi investigación doctoral. Allí el caso de Chile es comparado con el de Argentina y Uruguay. Asimismo, en tal investigación se revisan diversas hipótesis que podrían dar respuesta a la pregunta ¿por qué ante un problema de características similares se producen respuestas diferentes en estos tres países?, y que por la extensión del artículo omitimos. Tales hipótesis las podemos agrupar en teorías de elección racional y opinión pública; teorías de modernización y secularización de valores; teorías institucionalistas sobre sistema electoral, sistema de partidos y organización del gobierno; teorías sobre la influencia de las organizaciones de la sociedad civil en las políticas públicas; y teorías acerca de los efectos de los tratados internacionales vinculantes. También dada la extensión del presente artículo se han dejado afuera evidencias provenientes de entrevistas con los principales actores de la política y de otras fuentes como estadísticas o artículos periodísticos. 
de las políticas de drogas en Chile, que comienza en el gobierno de la Unidad Popular (1970-1973) cuando se aprueba en 1973 la ley 17.934 que por primera vez regula todo lo relativo al tráfico de estupefacientes en un solo cuerpo legal fuera del Código Penal. Este instrumento sería reemplazado por la dictadura militar en 1985 con la ley 18.403. Una vez retomada la democracia, se inicia el proceso que daría como resultado la ley 19.366 de 1995. Por último, diez años después se sanciona la actual ley 20.ooo que entre sus propósitos buscó penalizar el microtráfico. Finalmente analizamos el intento por regular el porte y el autocultivo de cannabis durante 2014-2015.

\section{Las políticas de drogas como políticas morales}

Desde la década de 1970, los investigadores comienzan a notar ciertos cambios en las prioridades de las sociedades industriales avanzadas. Un estudio clásico que aborda esta cuestión es el de Ronald Inglehart (1971), que evidenciaba las diferencias de valores entre las generaciones que nacieron antes de la Segunda Guerra Mundial, quienes se socializaron en condiciones de privaciones económicas, y aquellas cohortes que llegaron al mundo después de este suceso y crecieron en un contexto de prosperidad y con un Estado de Bienestar que reforzaba el sentimiento de que la supervivencia estaba asegurada ${ }^{3}$. Esta supervivencia garantizada habría permitido el desplazamiento en las prioridades desde 'valores materiales' hacia 'valores post-materiales'.

En los '70 temas como divorcio, aborto, eutanasia, derechos de las minorías sexuales, pena de muerte, entre otros entran en la agenda pública de los países desarrollados. Los académicos identificaron que estos asuntos están más afectados por valores sociales que por intereses económicos, es decir, que daban origen a un tipo de políticas distintas: las políticas morales. Podemos señalar dos polos en el estudio de las políticas morales, uno con sede en Estados Unidos y otro en Europa.

Un primer acercamiento, consideró que estas políticas se podían ajustar a la tipología propuesta por Theodore Lowi (1972) que clasificó las actividades gubernamentales en distributivas, regulatorias, redistributivas y constituyentes ${ }^{4}$. Por ello, la clásica obra de Tatalovich y Daynes, Moral Controversies in American Politics: Cases in Social Regulatory Policy, adopta la noción de regulación social, es decir, con estas políticas lo:

regulado no es una transacción económica sino una relación social. Pero el cambio en las relaciones sociales puede dar lugar a demandas de los ciudadanos para que la autoridad legal sea usada para afirmar el orden normativo tradicional, o modificarlo, o sancionar normas de comportamiento enteramente nuevas ${ }^{5}$.

3. INGLEHART (1971).

4. LOWI (1972).

5. TATALOVICH y DAYNES (1998) p. xxx. 
En los ‘9o, los estudios sobre políticas morales buscarán refinar las definiciones y probar en qué difieren este tipo de políticas respecto de las no morales. Referentes de Estados Unidos convergen en distinguir cuatro características: la primera, es que las políticas morales validan un conjunto particular de valores básicos sobre los cuales no existe un consenso completo en la comunidad; es decir, al menos una significativa minoría de ciudadanos tiene un conflicto fundamental con los valores primarios incorporados en la política moral. Así, lo que predomina en el debate es qué valores la sociedad debería validar y no cuál es el mejor modo de alcanzar los objetivos de la política. Un segundo rasgo, asociado a la característica anterior, es que estas políticas son técnicamente más simples que el resto; esto en el sentido de que al discutirse valores y no evidencias científicas -por ejemplo-, cualquiera puede considerarse legítimamente bien informado. La tercera particularidad, radica en la falta de compromiso por parte de las partes del debate, de manera que los "perdedores" retendrán sus posiciones y continuarán buscando su validación. Por último, este "choque" de valores hace que estos temas sean altamente sobresalientes para el público en general ${ }^{6}$.

La literatura estadounidense centrará su definición de este tipo de políticas entorno al enmarcado (framing) que se hace de los asuntos, más allá del contenido de la política. De modo que cualquier política puede ser calificada de moral si por lo menos una de las partes relevantes involucrada en el debate realiza sus argumentos para oponerse en términos morales -sobre todo religiosos-, más que por otras consideraciones ${ }^{7}$.

Otro núcleo académico relevante en el estudio de las políticas morales se encuentra en Europa. Allí la discusión avanzó a través de estudios comparativos. Una de las propuestas más destacadas es la de Engeli, Green-Pedersen y Larsen incluida en la obra Morality Politics in Western Europe. Parties, Agendas and Policy Choices (2012).

El objetivo general del libro es dar cuenta de la variación que existe en este tipo de regulaciones entre países. Su marco se formula a partir de la articulación de la teoría de agenda setting y la literatura sobre clivaje de partidos en Europa Occidental, particularmente en la emergencia de disputas entre partidos confesionales y seculares. Entonces, las nociones de mundo religioso versus el secular refieren a si ha emergido en el sistema de partidos un clivaje entre agrupaciones de base religiosa (por ejemplo, Democracia Cristiana) o con fuertes vínculos (como el Partido Popular español) y aquéllos seculares; no alude a si las poblaciones de esos países son muy religiosas ni a la relación formal entre Estado e Iglesia ${ }^{8}$.

\footnotetext{
6. MOONEY (1999).

7. MOONEY y SCHULDT (2008).

8. ENGELI et al. (2012).
} 
Luego de exponer el marco teórico, Engeli et al. hacen una breve definición de qué son las políticas morales, y sostienen que son las que abordan preguntas fundamentales como la muerte, la reproducción y el matrimonio. Para estos autores cuestiones como la regulación del tabaco, las apuestas o la prostitución no deberían ser entendidos como asuntos morales ya que no implican conflicto entre actores religiosos y seculares. Sin embargo, para otro grupo de académicos europeos estos temas sí son abordables como asuntos de política moral.

El proyecto sobre políticas morales encabezado por Christoph Knill parte de una crítica a la definición realizada por los núcleos académicos expuestos. Respecto del enfoque estadounidense, observan que al tomar como punto de partida que las políticas morales son resultado del proceso de las políticas, así como del encuadre (framing) que se hace de los temas como morales o no morales, genera una definición situacional que evita ex ante cualquier especificación de la política moral que sea generalizable a través del tiempo y el espacio ${ }^{9}$. Y en relación a la perspectiva de Engeli et al., cuestionan que al centrarse en la materia a ser regulada y si ésta refiere a conflictos en los valores sociales, "adopta una perspectiva nominal, clasificando a priori las políticas como de asuntos morales o no morales"10.

Para superar estas dificultades, Knill (2013) propone tomar como criterio de clasificación de las políticas a las constelaciones de intereses subyacentes, distinguiendo entre políticas morales manifiestas, latentes y no morales. Las políticas morales manifiestas refieren a aquellos temas en los que los valores tienen un papel central y el conflicto determina la toma de decisiones; los valores cobran relevancia como instrumento de poder político y social, de modo que diferentes actores o grupos pueden ganar o perder poder si ciertas creencias prevalecen o cambian: los casos típicos son los asuntos llamados de "vida y muerte", como el aborto, la eutanasia o la utilización de células madres humanas ${ }^{11}$.

Por su parte, el autor define a las políticas morales latentes como aquellas que tratan de temas en los cuales el conflicto de valores no es lo primordial, pero -bajo ciertas condiciones- podrían ser "explotados moralmente" ya sea para alcanzar objetivos políticos o económicos: ejemplos donde prevalecen estas constelaciones es en la regulación de la pornografía, el control de armas o de drogas.

A los fines de este trabajo se considera que la propuesta de Knill (2013) es la más adecuada, porque al considerar la política de droga como política moral latente nos permite explorar si para el caso de Chile se activó o no como un asunto de carácter moral.

9. HEICHEL et al. (2013).

10. HEICHEL et al. (2013).

11. KNILL (2013). 


\section{Los esquemas cognitivo-normativos de las clases dirigentes}

La política de drogas como política moral latente contiene elementos que la pueden activar en términos de valores sociales, es decir, que puede ser explotada moralmente. Si bien durante todo el proceso de la política surgirán oportunidades para activarla en estos términos, son las fases iniciales de reconocimiento y definición del problema, así como la propia formulación de la respuesta cuando más posibilidades tienen los actores para hacerlo. En esta dinámica son claves los esquemas cognitivo-normativo que prevalecen en los tomadores de decisiones.

$\mathrm{Y}$ aquí radica nuestra propuesta teórica, en la articulación de dos enfoques: las políticas morales y las ideas. Entendemos por esquemas cognitivo-normativo la articulación de ideas y valores compartidos que delinean las relaciones de causa-efecto que orientan a los decisores y que residen en el trasfondo de los debates. Esta propuesta conceptual tiene su origen en la literatura sobre el rol de ideas en las políticas públicas, y vincula dos elementos presentes en ella: la dimensión cognitiva, que refiere a ordenar, retener y comprender la información sobre el mundo, y la dimensión normativa que refiere a la capacidad de los actores de juzgar sobre la base de valores y normas si una elección en una situación dada es buena o mala ${ }^{12}$.

Las explicaciones ideacionales sostienen que "las personas actúan en función de elementos cognitivos y/o afectivos que organizan sus pensamientos [...]"13. Alan Jacobs distingue que la teoría ideacional como teoría causal es aquella en la que el contenido de una estructura cognitiva influye en las respuestas de los actores a una situación de elección, y tal estructura cognitiva no es totalmente explicable por las características materiales de la situación de elección ${ }^{14}$.

El principal rasgo de una explicación ideacional es que se trata de un argumento particularista y contingente. Este tipo de investigaciones muestran que en determinado momento histórico se eligió un conjunto de ideas -cuando también se podría haber seleccionado otro- que marcó el devenir de la situación; aunque se pudieran repetir la situación inicial podría resolverse de otra manera, con diferentes consecuencias causales. Es decir, no es la situación en sí misma la que le indica al actor cómo proceder sino la interpretación que éste haga de la situación, con la cual reduce sus opciones.

12. SCHMIDT (2008).

13. PARSONS (2007) p. 12.

14. JACOBS (2014) p. 43. 
Otra característica de la lógica ideacional es que refiere a "que ciertas personas históricamente situadas desarrollan sus propias maneras de interpretar el mundo que les rodea, y que esto determina su forma de actuar. Cualquier afirmación ideacional se enmarca en torno a personas concretas: los trabajadores de la Inglaterra del siglo XIX, los habitantes de una cierta región ucraniana, los miembros del Partido Socialdemócrata Alemán, etc."15.

Consideramos que las ideas son afirmaciones subjetivas que incluyen descripciones del mundo, relaciones causales o la legitimidad normativa de ciertas acciones; se construyen social e históricamente, y se constituyen como fuente del comportamiento político ${ }^{16}$.

Dado que existe una variedad de tipos de ideas y de sus efectos, algunos autores parten de la clasificación propuesta por John Campbell (2004) que las ordena según dos criterios, dónde operan en el debate -si en el primer plano o en el fondo- y si son normativas o cognitivas. Entonces, "las ideas pueden ser ideas subyacentes y, a menudo, suposiciones aceptadas que residen en el trasfondo de los debates sobre la toma de decisiones", o bien "pueden ser conceptos y teorías que se encuentran en el primer plano de estos debates, donde son articuladas explícitamente por las élites que toman las decisiones" ${ }^{17}$. Aclara el investigador que, si bien las ideas de fondo pueden ser visibles para los actores, se dan por sentadas, son ampliamente aceptadas e incuestionadas, por el contrario, las ideas que juegan en el primer plano son rutinariamente impugnadas como parte normal de cualquier debate de toma de decisiones. Por estas características, las ideas que operan en el trasfondo del debate tienden a limitar el cambio, mientras que las ideas en el primer plano, son objetadas y a menudo utilizadas para cuestionar el statu quo, tienden a facilitar cambio ${ }^{18}$.

La otra dimensión que varía para este autor es la naturaleza de las ideas, que puede ser cognitiva o normativa. Como toda esquematización, esta tipología tiene algunas limitaciones, por ejemplo, estas distinciones entre las ideas cognitivas y normativas, y entre las ideas de primer plano y de fondo se pueden considerar demasiado rígidas. Justamente esta limitación de la separación de la dimensión cognitiva de la normativa es la que pretendemos superar con los esquemas cognitivo-normativos que articula a ambas.

\footnotetext{
15. PARSONS (2007); BÉLAND (2019) p. 4.

16. PARSONS (2002); BÉLAND (2019).

17. CAMPBELL (2004) p. 93.

18. CAMPBELL (2004).
} 


\subsection{Los esquemas cognitivo-normativos y las politicas morales}

Las políticas morales ponen de manifiesto un elemento clave de las relaciones Estadosociedad: la forma en que los Estados regulan los comportamientos individuales a través de diferentes tipos de sanciones ${ }^{19}$. En este sentido, los esquemas cognitivonormativos que prevalecen en las clases dirigentes podrían ser útil para el abordaje de otras políticas morales ya que se organizan en torno a tres componentes presentes en este tipo de políticas: la concepción del ciudadano; la consideración sobre la conducta; y la responsabilidad del Estado ante el fenómeno. Por ejemplo, en el caso del aborto, podemos pensar en la idea que predomina sobre las personas gestantes, cómo se estima la práctica de interrupción del embarazo y qué rol le cabe al Estado en materia de derechos sexuales y reproductivos.

En este artículo observamos cómo la dirigencia chilena concibe al ciudadano usuario de sustancias ilícitas; cómo considera la conducta de porte para uso personal de cannabis; y de qué modo debe intervenir el Estado para mediar la relación entre sustancias psicoactivas y los ciudadanos.

A diferencia de lo que ocurre en los países desarrollados donde la política de drogas es disputada por diferentes actores como expertos, sociedad civil organizada, partidos políticos, etc., en América Latina -por su enmarcado como asunto de seguridad y no de salud- ${ }^{20}$, la decisión inicial está concentrada en el o la titular del Poder Ejecutivo $^{21}$. Dado que quien ocupe tal cargo es parte de la clase política del país, nos abocamos al análisis del esquema cognitivo-normativo de tal grupo.

Planteamos que en materia de drogas se conformó un esquema cognitivo-normativo en la década de los ' 70 del siglo pasado cuando se reconoce públicamente como problema el consumo de sustancias ilícitas en Chile. Mostraremos cómo las ideas iniciales sobre el problema de las drogas han persistido históricamente a través de actualizaciones. A pesar de que el fenómeno del consumo se transformó fuertemente en el período que abarca esta investigación (1973-2015), podemos observar una invariabilidad de las ideas.

19. HURKA et al. (2017).

20. En LABIANO (2020a) se explica las consecuencias tanto académicas como políticas de que el problema de las drogas haya sido encarado primordialmente como un problema de seguridad.

21. Más allá de la fuerte influencia reconocida a la figura del titular del Poder Ejecutivo en los sistemas presidencialistas latinoamericanos, otros autores coinciden en que en materia de políticas de drogas el respaldo presidencial es decisivo para el cambio en la política REPETTO (2014); QUEIROLO et al. (2019); von HOFFMANN (2019). 


\section{La política de drogas chilena en relación al porte para consumo personal}

La historia de las políticas de drogas en Chile, escasamente estudiada por la academia, comienza en el gobierno de la Unidad Popular cuando se aprueba en 1973 la ley 17.934 que por primera vez regula todo lo relativo al tráfico de estupefacientes en un sólo cuerpo legal fuera del Código Penal ${ }^{22}$. Este instrumento sería reemplazado por la dictadura militar en 1985 con la ley 18.403, la única que sancionó la apología del uso de sustancias prohibidas. Una vez retomada la democracia, se inicia el proceso que daría como resultado la ley 19.366 de 1995. Por último, diez años después se sanciona la actual ley 20.000 que entre sus propósitos buscó penalizar el microtráfico.

Si hasta la década de los '6o el consumo de drogas fue marginal y confinado a los extremos sociales -las elites o los sectores populares-, a partir de esa década se expande entre los jóvenes de clase media a través de la marihuana. Desde la Colonia hasta inicio del siglo XX, Chile fue un destacado productor mundial de cáñamo, y, si bien durante aquella década quedaban pocas plantaciones ubicadas en el Valle del Aconcagua, éstas comenzaron a ser visitadas por jóvenes "para comprar sacos de cogollos a muy bajo precio o intercambiarlos por jeans importados con los campesinos", lo cual, con el tiempo derivó en robos y saqueos ${ }^{23}$. En 1964, se creó la Brigada de Represión del Tráfico de Estupefacientes y Juegos de Azar (BEJA). A penas cinco años después se aprobaba una reforma al Código Penal en lo relativo a delitos contra la salud pública, con la ley 17.155 del 11 de junio de 1969.

Según lo descrito por Eduardo Vergara, en el año 1970 la mencionada Brigada incautó 8o kilos de cocaína y "en base a este hallazgo y su simbolismo, el gobierno de la Unidad Popular tomaría la decisión de abordar este problema no sólo desde la perspectiva de quienes cometían delitos con su tráfico sino en los consumidores”24.

\subsection{La definición socialista del problema de las drogas (1971-1973)}

La Unidad Popular encarnaba un proyecto político de construcción de una nueva sociedad, el cual se veía amenazado por el consumo de drogas de la juventud, pilar fundamental de la empresa. Apenas siete meses después de asumir la presidencia, Salvador Allende envía al Congreso el proyecto de ley que busca reprimir el tráfico de estupefacientes. En el mensaje que acompaña la normativa propuesta define:

22. Las primeras medidas sobre sustancias peligrosas para la salud son incorporadas en el Código Penal en 1874 a través de los artículos $313^{\circ}$ y $314^{\circ}$. Luego en 1969 se incorpora por medio de la ley 17.155 el artículo $319^{\circ}$.

23. IBAÑEZ (2018) p. 50.

24. VERGARA (2016) p. 36. 
Desde hace un tiempo a esta parte se ha producido en nuestro país un notable aumento del consumo de drogas y estupefacientes, principalmente por la juventud.

Muchas y de variada índole son las causas de este fenómeno, pero todas ellas pueden remitirse a la mala estructuración de la familia y de la sociedad. Frente a un mundo sin horizontes cunden los mecanismos de evasión ${ }^{25}$.

El sujeto, el joven consumidor, es pasivo: es el subproducto de una sociedad de consumo que no le ofrece otros ideales que situaciones de violencia y discriminación; de la dominación cultural, ya que a través de las drogas se pretende difundir un estilo de vida que le es ajeno a su idiosincrasia; y víctima de la inescrupulosa búsqueda de ganancias de los traficantes que contribuyen a perpetuar la injusticia y a adormecer la juventud ${ }^{26}$.

En el discurso de inauguración del año escolar pronunciado el 25 de julio de 1971, Allende una vez más ilustra cómo comprende el uso de drogas por parte de los jóvenes "que no vuelan por su propia imaginación, sino que tienen que recurrir a las drogas para empinarse frente a los procesos pequeños de todos los días y de la miseria del hombre", y es a través de la acción de la educación que el Estado va a señalarle "la gran tarea dignificadora, arrancándola de la oscilación y el vicio, entregándole el más noble mandato que puede tener un joven: luchar por su patria, una nueva sociedad y un nuevo hombre en la colmena fecunda del trabajo" ${ }^{27}$.

En el proyecto enviado, entonces, definió que la persecución penal tenía que ser para los proveedores de sustancias ilícitas y no para los consumidores. Es decir, para abordar el consumo estableció sanciones en lugar de la pena privativa de libertad, lo que se conoce como descriminalización de la práctica, regla que se mantiene hasta nuestros días.

Otro rasgo destacable del proyecto es la distinción, en al menos, dos tipos de uso de drogas: a quien se sorprende consumiendo estupefaciente se los somete a una pericia médica a fin de que se califique la circunstancia y, por tanto, reciban una respuesta diferenciada por parte del Estado, de modo que si es definido como adicto se hace acreedor de un "tratamiento de recuperación" y si no lo es, se le obliga a "una medida educativa de colaboración con la autoridad y control médico temporal". El fin es la reinserción del desviado, o sea "inculcar en el infractor un sentido de responsabilidad social y a encausarlo por las vías de su compromiso para con la comunidad" ${ }^{28}$.

25. HISTORIA DE LEY 17.934 (s/f) p. 4.

26. HISTORIA DE LEY 17.934 (s/f) p. 4.

27. ALLENDE GOSSENS (1971).

28. ALLENDE GOSSENS (1971). 
El proyecto enviado por Allende al Congreso, dos años más tarde daría origen a la ley 17.934. De los debates en el Congreso se aprecia que hubo un amplio consenso entre la dirigencia del momento en la definición del usuario: "Como ha dicho el Honorable señor Bulnes, nadie por su propia voluntad, o más que eso, por su debilidad o su inclinación a aspectos anormales, cae en el consumo de las drogas, y el peligro existe porque hay un tráfico de estupefacientes que tiene un dinamismo tan grande, que hoy día la gente joven está expuesta a caer en cualquier momento en las garras de estos comerciantes" (Senador de Izquierda Cristiana, retomando lo dicho por Senador de Partido Nacional) ${ }^{29}$. Por tanto, correspondía castigar a estos corruptores de la juventud y no a los consumidores, lo cual queda plasmado en el segundo artículo de la ley que define que no son narcotraficantes quienes porten consigo sustancias psicoactivas siempre que "que justifiquen o sea notorio que están destinadas a la atención de un tratamiento médico o al uso personal exclusivamente" ${ }^{3^{\circ}}$.

Entonces respecto de la conducta prevalece la idea de descriminalización del porte, esto no evita que se tomen medidas "para colocar en un nivel de convivencia a quienes se han extraviado o se han marginado de la sociedad" (Izquierda Cristiana) ${ }^{31}$, y para ello se apela a una idea bastante difundida trasnacionalmente: la internación compulsiva para los habituados al consumo. Esta "desviación" en caso de no requerir tratamiento médico se intentará corregir a través de una medida de colaboración con la autoridad por un tiempo no superior a tres meses ${ }^{32}$.

Entre las cámaras del Congreso hubo serias diferencias respecto del proyecto, para superarlas se conformó una comisión mixta. Uno de los aspectos que provocó una fuerte discrepancia fue la propuesta hecha por el Senado de separar las sustancias en dos tipos, "aquellas que producen dependencia, y las que, sin acarrear los mismos efectos, son nocivas para la salud y no es conveniente su divulgación ni uso" y en consecuencia sancionar "con penalidad distinta el tráfico y elaboración de ambos tipos de drogas" (Partido Demócrata Cristiano, DC) ${ }^{33}$.

29. HISTORIA DE LA LEY 17.934 (s/f) p. 183.

30. Art. 2, Ley 17.934, de 1973.

31. HISTORIA DE LA LEY 17.934 (s/f) p. 183.

32. Art. 10, Ley 17.934, de 1973. Podemos observar que realmente no se buscaba criminalizar el consumo ya que, en su informe sobre modificaciones propuestas, la Comisión de Constitución, Legislación y Justicia de la Cámara de Diputados indica que "para acomodar la redacción de esta norma al criterio de que la colaboración con la autoridad no es propiamente una pena sino un medio o forma de lograr la corrección del consumidor de estupefacientes, reemplazó la palabra 'pena' por 'medida"' HISTORIA DE LA LEY 17.934 (s/f) p. 45.

33. HISTORIA DE LA LEY 17.934 (s/f) p. 116. 
La distinción propuesta por el Senado tenía como objetivo otorgar flexibilidad a los jueces ya que en la redacción del proyecto se otorgaba la misma pena (presidio menor en su grado máximo a presidio mayor en su grado medio) "a la persona mayor de 21 años que tiene un laboratorio gigantesco para preparar cocaína, que es el caso recientemente descubierto en las cercanías de Algarrobo, que el muchacho que va a Los Andes, consigue una mata de cáñamo y extrae de ella marihuana para su consumo personal" (Senador Partido Nacional corroborando lo dicho por sus pares demócratas cristianos) $)^{34}$.

Esta fue la idea que prevaleció, y cuando se reglamenta la ley, la planta de cannabis y sus resinas quedan catalogadas como sustancias que no producen daños considerables a la salud pública ${ }^{35}$. Así se mantendrá hasta el año 2008 cuando se la reclasifique como sustancia dañina, durante la primera gestión de Michelle Bachelet y que será una de sus promesas de campaña para su segundo mandato, revisar "el Reglamento que considera a la marihuana en la lista 1) entre las drogas más peligrosas" ${ }^{36}$.

Durante la dictadura militar de Augusto Pinochet se llevaron adelante profundas transformaciones en la economía y en la política. Sin embargo, con respecto al consumo de drogas no hubo cambios y se continuó por el camino de la descriminalización trazado por el gobierno de izquierda.

\subsection{Una nueva ley de drogas bajo la dictadura (1983-199o)}

Antes de abordar la elaboración la ley 18.403 hay que señalar que el material existente es muy escaso, y que prácticamente no hubo debate. No obstante, hay algunas cuestiones a destacar.

Como nuevos delitos se incorporaron la apología a las drogas o su propaganda, la asociación ilícita, y se habilitó la extradición tanto activa como pasiva de personas extranjeras. Respecto de la marihuana: "se penaliza con presidio a quienes sin contar con la competente autorización, siembren, cultiven, cosechen o posean especies vegetales o sintéticas del género cannabis, en circunstancias que hagan presumir el propósito de tráfico ilícito" ${ }^{37}$; también son penalizados los que abandonaren en lugares públicos o de fácil acceso plantas de las mencionadas ${ }^{38}$, lo cual se justificó en que la "situación se produce con frecuencia, lo que sin duda facilita su consumo especialmente por menores de edad" 39 .

34. HISTORIA DE LA LEY 17.934 (s/f) p. 144.

35. Decreto 535, de 1973.

36. PROGRAMA DE GOBIERNO MICHELLE BACHELET (2013) p. 103.

37. Art. 2, Ley 18.403, de 1985.

38. Art. 3, Ley 18.403, de 1985.

39. Informe técnico de los Ministros de Defensa Nacional, Educación Pública, Justicia y Salud al presidente, HISTORIA DE LA LEY 18.403 (s/f) p. 6. 
Al propósito de este artículo, continuó la descriminalización del porte para uso personal con la fórmula "a menos que justifiquen o sea notorio que están destinadas a la atención de un tratamiento médico o al uso personal exclusivamente" ${ }^{\prime 0}$. En el proyecto enviado por Pinochet se proponía definir con mayor precisión la medida de colaboración con la autoridad, ya que según él se aplicaba escasamente pese a su evidente contenido resocializador, pero en el trámite legislativo se argumentó que resultaba incongruente someter a tal sistema a una persona que no requiere atención médica especializada ni ha cometido delito ${ }^{41}$.

Durante la dictadura siguió predominando el esquema cognitivo-normativo que considera al usuario de drogas como un enfermo al que no hay que penalizar, sin embargo estuvo desafiado por una idea causal disponible en la época que consideraba al consumidor parte del narcotráfico ${ }^{42}$ y que estuvo encarnada por el General César Mendoza Durán, Director de Carabineros ${ }^{43}$.

Otra voz en contra de penalizar fue la de Fernando Matthei, el comandante en jefe de la Fuerza Aérea de Chile, quien afirmó: "Por ejemplo, sí aquí se trata de establecer en esta ley de que el uso o el consumo de drogas sea castigado, yo desde ya les digo que no estoy de acuerdo. Tenemos que ponernos de acuerdo, primero, sobre qué es lo que vamos a querer. Si mañana decimos: 'Señores, castigaremos al que consume drogas', desde ya digo: 'Un momento, yo no firmo eso"'44.

Finalmente, en consonancia con las Convenciones de Naciones Unidas, el cannabis se reguló a través de tres decretos del Ministerio de Salud, en dos de ellos reglamentando el Código Sanitario (404 y 405) y la ley 18.164 sobre legislación aduanera. Por último, el Decreto 67 es el que reglamenta el art. $1^{\circ}$ de la ley 18.403 por el cual se le permite al Tribunal "rebajar la pena hasta en dos grados cuando se trate de sustancias que no sean productoras de daños considerables a la salud pública”. Dentro de este grupo encontramos al cannabis.

Apenas retomado el régimen democrático se iniciará el proceso para suplantar esta ley.

40. Art. 5, Ley 18.403, de 1985.

41. Indicaciones Cuarta Comisión Legislativa, HISTORIA DE LA LEY 18.403 (s/f) p. 53.

42. Por ejemplo, en esta idea se sustenta el fallo Colavini de la Corte Suprema de Justicia de la Nación Argentina de 1978.

43. Veáse HISTORIA DE LA LEY 18.403 (s/f) pp. 92-93.

44. HISTORIA DE LA LEY 18.403 (s/f) p. 102. 
4.3 El retorno a la democracia y la permanencia del asunto en la agenda pública (1990-200o)

Con el regreso a la democracia el problema de las drogas entró de lleno en la agenda pública. A tan sólo seis meses del traspaso del mando, en la Cámara de Diputados -en sesión secreta- se conformó el 13 de septiembre de 1990 la Comisión Especial Investigadora del Problema de la Droga en Chile. Y el 22 de octubre de ese mismo año se creó el Consejo Nacional para el Control de Estupefacientes (CONACE) que tuvo como objetivo asesorar al Presidente en esta materia ${ }^{45}$.

La Comisión Especial de la Cámara de Diputados presenta en agosto de 1991 a la Sala su Informe, en tres ocasiones indica que “[...] dicho problema es real y concreto, no obstante que su exacta dimensión no ha podido ser claramente cuantificada en razón de que no existían cifras estadísticas que pudieran demostrar su real alcance" ${ }^{46}$.

Argumentando que "el tráfico ilícito de sustancias o drogas estupefacientes y psicotrópicas y su consumo indebido constituyen una seria alteración de la convivencia social y afectan de una u otra forma todas las actividades del país" ${ }^{47}$, el presidente $\mathrm{Pa}$ tricio Aylwin (DC) presentó en abril de 1992 un proyecto para sustituir la ley 18.403.

El proyecto del Ejecutivo introdujo un punto que provocó una discusión álgida en el Congreso y en el cual se observa la dimensión moral del uso de drogas al estipular que: "Sin desconocer la calidad de enfermo del consumidor habitual, se ha estimado necesario sancionar el consumo de estas substancias en lugares públicos o abiertos al público. La práctica de estas conductas se ha constituido en una verdadera propaganda o difusión de las mismas [...]" ${ }^{48}$. En consecuencia, el presidente propuso que quienes consuman o porten sustancias para su uso personal sean castigados "[...] con prisión en su grado mínimo o multa de un vigésimo de ingreso mínimo mensual o cuatro ingresos mínimos mensuales"49.

En el debate que dio origen a la ley 19.366 se retomó la perspectiva de los '70 centrada en los jóvenes como víctimas del narcotráfico: "Es evidente que los traficantes tienen un interés especial en convertir a los jóvenes en toxicómanos para expenderles una mayor cantidad de drogas en el futuro" (Renovación Nacional, RN) ${ }^{50}$. También como en los setentas, los jóvenes se refugian en la droga como producto de una crisis de valores: “[...] los jóvenes están sufriendo las consecuencias de estas verdaderas selvas que son nuestras ciudades; del exceso de tiempo libre de que disponen y, obvia-

\footnotetext{
45. Decreto 683, de 1990.

46. CÁMARA DE DIPUTADOS (1991) pp. 3123-3158.

47. HISTORIA DE LA LEY 19.366 (s/f) p. 5.

48. HISTORIA DE LA LEY 19.366 (s/f) p. 9.

49. HISTORIA DE LA LEY 19.366 (s/f) p. 9.

50. HISTORIA DE LA LEY 19.366 (s/f) p. 160.
} 
mente, de la problemática que afecta a las familias, además de la poca comunicación que se da en los hogares, muchos de los cuales están en crisis o desintegrados" ${ }^{51}$.

Atendiendo a esa concepción del uso de drogas, las respuestas por parte del Estado debían pasar por campañas de prevención centradas en recomponer los valores:

“[... es muy importante y tal vez más efectivo a largo plazo, el hecho de propender a la educación masiva de la población, estimulando el crecimiento normal y positivo de los individuos en todas las áreas del desarrollo, educando preventivamente en el sentido de mostrar como probable el hecho de caer en la drogadicción. Todo lo anterior, mostrándole al niño, joven o adolescente como fortalecer sus vínculos familiares lo que le proporcionara mejores armas para defenderse de caer en el flagelo de la droga" ${ }^{2}$.

Prácticamente no hubo mención al rol del Estado más allá de la forma penal de tratar la conducta. Y fue sobre este aspecto donde se recorrió un amplio espectro de posiciones, desde quienes abogaron por la llana penalización del consumo, pasando por aquellos que buscaron que a la propuesta presidencial de sancionar el uso en espacios públicos se le sumara la sanción al consumo privado.

Los congresistas que abogaban por una penalización con privación de la libertad argumentaban que "si queremos erradicar esta plaga, que está adquiriendo caracteres de epidemia en Chile, debemos tomar medidas muy rigurosas" (DC) ${ }^{53}$; estimaban que la libertad individual y la privacidad debían posponerse ante la salud pública. Sin embargo, primó la idea de que la cárcel no tendría un efecto rehabilitador sino todo lo contrario, se la calificó de verdadera escuela del delito:

En consecuencia, introducir el criterio de que puede haber pena de privación de libertad por el consumo de droga es completamente contradictorio con el fin social que se persigue: la recuperación de la gente sabemos que es mucha y que pertenece a todos los estratos, y, en especial a la juventud que ha caído en la adicción a la droga (Partido por la Democracia, PPD) 54 .

Otros legisladores consideraron que el proyecto presidencial de sanción al consumo público era insuficiente y que era necesario sancionar también el consumo privado siempre que las personas se hubiesen concertado con otras para ello. El razonamiento en el que se sostenía tal proposición era que en la privacidad se podría inducir al consumo a personas que no eran adictas o a menores, por lo cual la conducta trascendía al ámbito social:

51. HISTORIA DE LA LEY 19.366 (s/f) p. 144.

52. Proposiciones, Informe de la Comisión Especial Investigadora del Problema de la Droga en Chile CÁMARA DE DIPUTADOS (1991) p. 3162.

53. HISTORIA DE LA LEY 19.366 (s/f) p. 712.

54. HISTORIA DE LA LEY 19.366 (s/f) p. 707. 
De tal manera que si queremos enfrentar esta situación, que es dramática, tenemos que llegar hasta el extremo, aparente, de ejercer un control en lo que reviste el carácter de recinto privado, a fin de poder salvar a un sector importante de nuestra juventud (PPD) ${ }^{55}$.

Nuevamente aparece este elemento moral del contagio: "[...] no es que se sancione en cuanto el recinto es privado, sino en cuanto a que en un recinto privado se comete un acto de trascendencia social, como es el concierto para la finalidad indeseable de inducir en el consumo de drogas a alguien que no es adicto" (RN $)^{56}$.

Finalmente, respecto de la conducta de porte o consumo de drogas en público, recordemos que la ley del año '73 sancionaba aplicando una "medida de colaboración con la autoridad", lo cual fue dejado de lado en la ley de la dictadura y se retoma en los '9os. En el debate democrático prevaleció la idea de que era necesario sancionar esta conducta como falta, para evitar la propagación de un accionar inmoral y como medio de resocialización: "las penas que se establecen son simbólicas, entregan señales: tienden a alertar, a ayudar o a facilitar, sobre todo, la prevención o la corrección de quienes se inician en el consumo de la droga. Los enfermos por ella, sin duda, requieren tratamiento de rehabilitación de otra magnitud" (DC) $)^{57}$.

La ley 19.366 publicada en 1995 tiene un título denominado "De las faltas y su procedimiento", el cual a través de ocho artículos abordó las sanciones para quienes porten drogas para consumo en espacios públicos o en recintos privados siempre que se hubieren concertado con tal propósito. Las medidas son: a) Multa de media a diez unidades tributarias mensuales y b) Asistencia obligatoria a programas de prevención hasta por sesenta días, en instituciones consideradas como idóneas por el Servicio de Salud de la ciudad asiento de la Corte de Apelaciones respectiva.

Con respecto al cannabis, se establece que el cultivo destinado al uso o consumo personal exclusivo y próximo en el tiempo será sancionado según los artículos 41 y siguientes ${ }^{58}$. También se indica que el Servicio Agrícola y Ganadero será el organismo estatal encargado de otorgar la autorización para los cultivos legales a escala ${ }^{59}$. La ley 19.366 mantuvo la distinción entre el daño que producen las sustancias y la posibilidad de que el juez rebaje la pena, en tal sentido el Decreto 565 que la reglamenta -ya no dictado por el Ministerio de Salud sino por el de Justicia- ubicó como se hizo en el '73 y en el ' 85 al cannabis en la lista de sustancias que no producen dependencia física

55. HISTORIA DE LA LEY 19.366 (s/f) p. 714.

56. HISTORIA DE LA LEY 19.366 (s/f) p. 715.

57. HISTORIA DE LA LEY 19.366 (s/f) p. 348.

58. Art. 2, Ley 19.366, de 1995.

59. Art. 2, Ley 19.366, de 1995. 
o síquica ${ }^{60}$. A nivel de regulación de medicamentos, seguirán vigentes las clasificaciones hechas por los Decretos 404 y 405 de la dictadura.

Pocos meses después de publicada la nueva normativa, considerando "que el flagelo de las drogas es un mal que continúa avanzando en nuestro país" y en consecuencia "que sólo una preocupación metódica, sistemática y continua permitirá hacer retroceder este flagelo que ataca principalmente a niños y jóvenes en nuestro país”, los Diputados decidieron reconstituir la Comisión de Drogas la cual tendría vigencia hasta el final del período legislativo ${ }^{61}$. Éste fue el puntapié para la elaboración de la última ley de drogas chilena, la 20.00o, que desarrollamos a continuación.

\subsection{La ley 20.ooo y el endurecimiento de la penalización del cannabis}

La ley 19.366 llevaba poco más de un año y medio en vigencia cuando la Comisión Especial de Drogas de la Cámara de Diputados presentó su Informe. Uno tras otro los distintos expertos invitados por la Comisión dieron cuenta de una situación: si bien en la ley hay distinción de penas por la sustancia traficada no la hay respecto de las cantidades lo cual provoca que se apliquen altas penas a traficantes primerizos o con poca cantidad, situación que se ve agravada porque la ley no prevé la posibilidad de penas alternativas a la prisión.

En 1998 al comenzar un nuevo periodo legislativo se acuerda la reconstitución de la Comisión Especial de Drogas, que retomaría el trabajo de la anterior y evaluaría los proyectos presentados al momento ${ }^{62}$. Nuevamente, al presentar su informe un año después, hay consenso de que la principal falencia se encuentra en la rigidez de las penas establecidas para los traficantes y que se aplican a una gran cantidad de personas que comercian pequeñas cantidades, lo cual -a su vez- provoca la saturación del sistema carcelario ${ }^{63}$. De modo que distinguir y penalizar el microtráfico será el principal objetivo de la reforma a la ley de drogas.

Dado que el porte de drogas para consumo personal exclusivo y próximo en el tiempo no está penalizado, la dirigencia chilena consideró que los jueces no aplicaban penas de hasta diez años de prisión que fueron pensadas para narcotraficantes y, en cambio, optaban por considerar las pequeñas cantidades como uso personal. Según lo expresado por el presidente Eduardo Frei Ruiz Tagle (DC) en el Mensaje que acompañó el proyecto de ley: "Ello ha producido un mayor daño social que el perjuicio individual que se trataba de evitar, en la medida que constituye una grave señal que puede incentivar tales conductas" ${ }^{64}$.

60. Decreto 565, de 1996.

61. CÁMARA DE DIPUTADOS (1995).

62. CÁMARA DE DIPUTADOS (1998).

63. CÁMARA DE DIPUTADOS (1999).

64. HISTORIA DE LA LEY 20.000 (s/f) p. 5. 
A raíz de esta interpretación, el debate por la tenencia de sustancias psicoactivas para uso personal será central. En el proyecto del Ejecutivo se optó por continuar con la despenalización y generar herramientas para que el juez razonara el destino de la posesión. Sin embargo, la propuesta de la Comisión Especial sostenía que ya que a los magistrados se les dificultaba precisar si el porte de drogas es para consumir o vender, la manera más eficaz de lidiar con el microtráfico y dificultar la distribución de drogas era castigar con presidio a toda persona que tuviese en su poder sustancias ilícitas: "Esta modificación es fundamental, porque hoy muchos jueces califican el microtráfico como consumo y, de esa forma, se ha expandido este flagelo en la mayoría de las poblaciones, lo que ha incrementado el alto índice de drogadicción (Unión Demócrata Independiente, UDI) ${ }^{65}$. Según los legisladores de esa manera se pondría un freno al fenómeno del "uso de consumidores como microtraficantes por las organizaciones delictuales, como canal de distribución amparado por la impunidad que deriva de la actual interpretación judicial" (Comisión de Constitución) ${ }^{66}$.

La propuesta de la Comisión de Drogas suponía que penalizar el porte de drogas no era lo mismo que castigar el consumo. Rápidamente otros legisladores notaron la contradicción de la fórmula:

[...] según la tesis de la Comisión Especial de Drogas, si una persona es descubierta portando droga, le convendría consumirla con el objeto de ser sancionada por una falta, y no por portarla, porque en tal caso se le sancionaría por un delito. Llegamos al absurdo de que al que porta droga le convendría, frente a la sorpresa policial, consumirla rápidamente para obtener una menor sanción $(\mathrm{DC})^{67}$.

Considerando que el uso de drogas es un fenómeno sanitario, los legisladores se opusieron a la penalización del porte para consumo personal con ideas como alejar a las personas de los servicios de salud, la saturación del sistema carcelario o la libertad individual. De este modo, si bien se arribó a la penalización de los microtraficantes -entendidos como aquellos que portan "pequeñas cantidades” de drogas- se eximió del presidio a los que logren justificar que tales sustancias están destinadas "a la atención de un tratamiento médico o a su uso o consumo personal exclusivo y próximo en el tiempo" ${ }^{68}$. Además, para colaborar con la tarea del juez se incluye que:

65. HISTORIA DE LA LEY 20.000 (s/f) p. 705.

66. HISTORIA DE LA LEY 20.000 (s/f) p. 392.

67. HISTORIA DE LA LEY 20.000 (s/f) p. 356.

68. Art. 4, Ley 20.000, de 2005. 
Se entenderá que no concurre la circunstancia de uso o consumo personal exclusivo y próximo en el tiempo, cuando la calidad o pureza de la droga poseída, transportada, guardada o portada no permita racionalmente suponer que está destinada al uso o consumo descrito $[\ldots]^{69}$.

Es destacable el presupuesto cognitivo con el que opera la dirigencia chilena: considerar que en un mercado ilícito quien porte algún psicoactivo tiene información de la calidad o pureza del bien en cuestión, y que sólo quien trafica puede tener un producto de calidad.

La nueva ley 20.00o sancionará a quienes porten o consuman drogas en espacios públicos o en recintos privados, si se hubiesen concertado para tal propósito ${ }^{70}$. A las penas de multa de una a diez UTM y asistencia obligatoria a programas de prevención, se suma la "participación en actividades determinadas a beneficio de la comunidad, con acuerdo del infractor y a propuesta del departamento social de la municipalidad respectiva [... ${ }^{\prime 71}$. En la misma falta incurrirá quien plante cannabis para uso personal ${ }^{72}$.

Nuevamente, primó la idea de que la ausencia de pena es lo que permite que quienes acuden a un tratamiento de rehabilitación no teman ser denunciados ante las autoridades, pero el consumo en público no deja de ser visto como propagador de una actividad inmoral:

es imposible sancionar el consumo privado, porque significaría convertir la potencialidad del tratamiento en la complicidad de un delito, pero tampoco es admisible una norma permisiva. Si bien el consumo puede ser tolerado a nivel privado, el consumo a nivel público tiene que ser sancionado con mucha fuerza $(\mathrm{DC})^{73}$.

Para los años dos mil cuando se da este debate, la sociedad chilena ha ampliado su uso de drogas. No obstante, el esquema cognitivo predominante en la dirigencia chilena respecto del problema, los usuarios y el rol que le compete al Estado es muy similar al que delineamos en los debates pasados en términos de los traficantes corrompiendo a la juventud:

69. Art. 4, Ley 20.000, de 2005.

70. A pesar de que en el debate legislativo en reiteradas oportunidades se mencionó que "no hay ninguna persona procesada por consumo de drogas que haya sido descubierta en un lugar privado previa concertación, o sea, el consumo privado concertado no es eficaz en la práctica". HISTORIA DE LA LEY 20.000 (s/f) p. 510.

71. Recordemos que en 1973 se estableció también como sanción una medida de colaboración con la autoridad cuando se tratare de un consumidor que no requiera tratamiento médico (art. 10, Ley 17.934, de 1973).

72. Art. 8, Ley 20.000, de 2005.

73. HISTORIA DE LA LEY 20.000 (s/f) p. 511. 
[...] no es el consumo el verdadero y más grande problema, puesto que los delitos no están asociados a él, sino al tráfico, a las personas que promueven el consumo mediante el obsequio de drogas a jóvenes y niños, y una vez que los dominan y pasan a pertenecer a su círculo, les exigen que consigan nuevos consumidores para mantener y hacer crecer su oferta y su negocio. ¡Eso es lo que se debe combatir! (DC) ${ }^{74}$.

A su vez los jóvenes usan drogas por una crisis de valores o evasión de la realidad que el Estado tiene que subsanar:

[...] un combate eficaz contra la droga no puede eludir la pregunta de por qué en nuestro mundo contemporáneo crece la angustia frente a la realidad cotidiana hasta el punto de impulsar a cantidades cada vez mayores de personas a ingresar en el circuito infernal de la droga. ¿Qué pasa en nuestro mundo contemporáneo que el consumo de drogas se hace tan atractivo para nuestra gente, en especial, para los jóvenes? (Independiente) ${ }^{75}$.

En consecuencia, la solución que se propone:

Sin duda, la mejor manera de evitar que se trafique y que se consuma droga es teniendo la capacidad de formar con claridad a los jóvenes, haciéndoles presente que la droga les hace mal porque destruye sus vidas, que les hace mal a sus familias y que termina por crearles una enorme frustración personal y espiritual $(\mathrm{RN})^{76}$.

De los 39 legisladores que conformaron la Comisión Mixta que cerró el debate y redacción de la ley 20.ooo, sólo uno votó en contra: el Senador Nelson Ávila, del Partido Radical Socialdemócrata. Durante el debate tuvo una postura muy crítica, señaló que ningún país había registrado avances respecto del flagelo aplicando legislación represiva y que la ley que se discutía sería un eslabón más de la cadena de fracasos, camino al que Chile era arrastrado por los sectores más conservadores de la socie$\operatorname{dad}^{77}$. Pero el Senador fue más allá y, en medio del debate, presentó un proyecto para despenalizar el autocultivo.

La propuesta que entró al recinto el 1ro de julio de 2003 se sostuvo en dos argumentos:

74. HISTORIA DE LA LEY 20.000 (s/f) p. 349.

75. HISTORIA DE LA LEY 20.000 (s/f) p. 191.

76. HISTORIA DE LA LEY 20.000 (s/f) p. 166.

77. Véase HISTORIA DE LA LEY 20.000 (s/f). 
Legalizar el cultivo para su uso o consumo personal exclusivo y próximo en el tiempo permitirá a los usuarios abastecerse sin tener que depender de las redes de tráfico. También posibilita disponer de un producto sin adulterar, de mayor calidad y con menores riesgos para la salud ${ }^{78}$.

Es decir, Ávila consideraba que si lo que se busca es proteger la salud y seguridad de la ciudadanía, ésta era una forma más eficiente que la prohibición.

La discusión sobre el proyecto ingresó al pleno con el rechazo unánime por parte de la Comisión de Constitución, Legislación, Justicia y Reglamento. Allí nuevamente se evidenció el esquema cognitivo-normativo de la dirigencia chilena: el consumo.

tiene que ver con aspectos más generales, culturales, de nuestra sociedad: falta de sentido de la vida, ausencia de comunidades más activas, crisis de la familia, exclusión social; es decir, un conjunto de causas muy profundas que llevan a las personas -jóvenes y no tan jóvenes- al consumo de drogas (Partido Socialista de Chile, PS) ${ }^{79}$.

Se defendió la despenalización de la conducta en términos de que no sería conveniente aplicar pena de privación de la libertad a quien se "autodestruye", ya que se lo alejaría de los tratamientos de rehabilitación que requiere. Respecto de las responsabilidades del Estado, correspondía reforzar la prevención.

A diferencia de los debates anteriores, acá podemos observar específicamente lo que atañe al objeto de este trabajo: el esquema cognitivo-normativo de la dirigencia chilena respecto del uso personal de cannabis. En tal sentido, queremos destacar dos cuestiones: una, los vínculos lógico-causales respecto de la sustancia que se expusieron. Con excepción de Ávila, todos los legisladores indicaron que estaba científicamente comprobado que el consumo de marihuana era el paso previo para el uso de drogas duras. Casi todos mencionaron los distintos daños que produce, llegando al extremo de afirmar que "va asesinando paulatinamente las neuronas de quienes la consumen. Reitero: va asesinando, matando, las neuronas" (DC) ${ }^{80}$.

El otro punto a resaltar -que no es privativo de la dirigencia chilena- es la desconfianza en la ciudadanía: "Tampoco se puede descartar que quienes planten cannabis en sus casas puedan empezar a abastecer a su entorno inmediato, abriendo una puerta a la comercialización y al microtráfico" $(\mathrm{RN})^{81}$.

78. BOLETÍN 3269-07 (2003).

79. CÁMARA DE SENADORES (2005).

80. CÁMARA DE SENADORES (2005).

81. CÁMARA DE SENADORES (2005). 
Si bien varios senadores pusieron de relieve la importancia y necesidad del debate sobre este asunto, y le reconocieron a Ávila el mérito de provocarlo, el proyecto fue rechazado por los votos negativos de todos los legisladores excepto el del proponente. Dos meses después, el Senador Nelson Ávila presentó otro proyecto que tenía como objetivo autorizar el autocultivo de cannabis para fines terapéuticos ${ }^{82}$. A diferencia de la propuesta anterior, ésta sólo fue remitida a la Comisión de Salud y allí fue archivada años más tarde.

La ley 20.00o fue sancionada en 2005 y se reglamentó tres años más tarde mediante el decreto 867 del Ministerio del Interior, y por primera vez desde 1973 la planta de cannabis fue catalogada dentro de la lista de sustancias "productoras de dependencia física o síquica, capaces de provocar graves efectos tóxicos o daños considerables a la salud" y por ello quien es juzgado como traficante de marihuana no puede acceder a una rebaja de la pena.

Sin embargo, al igual que en las dos leyes precedentes, se contempla en el artículo 9 la posibilidad de solicitar una la autorización por parte del Servicio Agrícola Ganadero para un cultivo lícito. Será esta medida la que habilitará a la sociedad civil a realizar la primera plantación de cannabis legal a gran escala en América Latina, nos referimos a la experiencia de la Fundación Daya y el Municipio de La Florida ${ }^{83}$.

En el siguiente apartado abordamos el proceso legislativo que en 2015 dio media sanción al autocultivo de hasta 6 plantas de cannabis y la despenalización del porte de hasta 10 gramos de la misma sustancia.

\subsection{Proceso político y respuesta parcial: el reconocimiento terapéutico del cannabis}

En 2011, bajo el gobierno de centro-derecha de Sebastián Piñera (2010-2014), se aprueba una reestructuración del Ministerio del Interior, y el CONACE como dependencia del mismo también es actualizado: se convierte en Servicio Nacional para la Prevención y Rehabilitación del Consumo de Drogas y Alcohol (SENDA), esta modificación implicó que se le otorgara más capacidad para el desarrollo de sus actividades y que -a diferencia del organismo que lo precedió- ya no ejerciera funciones relacionadas con el control de la oferta de sustancias ilícitas ${ }^{84}$.

No obstante, tanto actores de la sociedad civil como legisladores, no acuerdan con que esta dependencia esté en la órbita del mencionado ministerio. Así lo declararon los senadores Ricardo Lagos Weber (PPD), Juan Pablo Letelier (PS) y Fulvio Rossi (PS) en su proyecto de ley, donde afirman que se debería considerar un cambio de enfoque y establecer que las políticas públicas en materia de drogas sean dirigidas por el

82. BOLETÍN 3812-07 (2005).

83. LABIANO (2020b) pp. 161-163.

84. Ley 20.502, de 2011. 
Ministerio de Salud, y el SENDA depender de dicha cartera ${ }^{85}$. En esta iniciativa también propusieron la exención de la responsabilidad penal del autocultivo y el porte o transporte de cannabis para consumo personal ${ }^{86}$. Si bien otros senadores alentaron el debate, la propuesta fue archivada. Como apunta Eduardo Vergara, los proyectos de Ávila o de Lagos Weber, Letelier y Rossi, si bien "no prosperaron en el debate ni en su aprobación pero sí fueron llenando un vacío importante en la contingencia nacional para servir de base para debates posteriores" ${ }^{87}$.

Durante el 2013 una serie de sucesos pusieron el asunto de la regulación de la marihuana en el debate público, preparando el terreno para que al año siguiente entrase en la agenda parlamentaria. Ese año se dieron tres detenciones vinculadas a la sustancia que adquirieron atención mediática (los casos del médico psiquiatra Milton Flores, que llegó incluso a la Corte Interamericana de Derechos Humanos; el del actor Ariel Mateluna; y el del productor Manuel Lagos). Asimismo, en mayo se presentó el Informe sobre el Problema de las Drogas en las Américas de la OEA, momento en que la Secretaría General del organismo estaba a cargo del ex Ministro del Interior (20oo2005) y actual senador chileno, José Miguel Insulza (2018-2026) ${ }^{88}$.

El intenso proceso legislativo que se dio en torno al posible reconocimiento legal del autocultivo y la remoción de sanciones para el porte personal de cannabis inicia en enero de 2014 cuando se publica el informe sobre la ley 20.000 elaborado por el Comité Evaluación de la Ley de la Cámara de Diputados, allí se indica que si bien la posesión de pequeñas cantidades para el uso personal es una conducta lícita, "no obstante, esa finalidad no se estaría cumpliendo, porque de todas formas el consumidor requiere tener acceso a la sustancia, comprarla, cultivarla, proveérsela de algún modo" 89 .

En marzo se hace público que la saliente directora del SENDA, Francisca Florenzano, había elaborado un decreto para cambiar la clasificación de la marihuana como sustancia productora de graves efectos a la salud. También en ese mes, los medios de comunicación reportan los datos del estudio de la consultora "Plaza Pública Cadem" según los cuales un 65\% de los chilenos entrevistados consideran que la marihuana es una droga blanda, incluso un $54 \%$ de las personas que nunca la han probado son de

85. BOLETÍN N ${ }^{\circ} 8.510-07$ (2012).

86. BOLETÍN N ${ }^{\circ} 8.510-07$ (2012).

87. VERGARA (2016) p. 95.

88. En el informe que aborda de manera integral el problema de las drogas en la región se indica que: "El cultivo para uso personal podría prevenir los peligros de la expansión del consumo asociada con la venta comercial al detalle y permitir a las personas producir para su propio uso y quizás para regalarlo o compartirlo en un pequeño colectivo. Aun en el contexto de la prohibición, el cultivo para el uso personal puede tener un tratamiento diferente [...]”. OEA (2013) p. 91.

89. COMITÉ EVALUACIÓN DE LA LEY (2014) p. 35. 
esta opinión; además un $78 \%$ de los encuestados está de acuerdo con que "Se autorice la venta de marihuana con receta médica para uso medicinal"90.

El 23 de julio se presenta en el Senado el proyecto "que modifica la ley $\mathrm{N}^{\circ} 20.000$ con el objeto de despenalizar el auto cultivo, cosecha, porte o consumo, regulados a escala individual, de plantas vegetales del género cannabis, cuando esas conductas se funden en razones de índole personal, terapéutica o espiritual" ${ }^{91}$ de autoría de los senadores socialistas Isabel Allende, Alfonso De Urresti, Juan Pablo Letelier, Carlos Montes y Fulvio Rossi; el proyecto ingresa y pasa a Comisión de Constitución, Legislación, Justicia y Reglamento y allí queda hasta ser archivado cuatro años después.

Ese mismo día ingresan, pero en la cámara de Diputados, el proyecto de Resolución $\mathrm{N}^{\circ} 123$ y un proyecto de ley. En el primero, los legisladores acordaron "solicitar a la Presidenta de la República, señora Michelle Bachelet Jeria, la modificación de los decretos 404 y 405, del Ministerio de Salud, y del decreto 867, del Ministerio del Interior, a fin de facilitar el acceso a tratamientos y medicamentos derivados de la especie vegetal cannabis sativa" ${ }^{92}$. Por su parte, los diputados de Amplitud, Karla Rubilar, Pedro Browne, Joaquín Godoy y Matías Walker por la DC patrocinaron el proyecto que "Modifica la ley $\mathrm{N}^{\circ} \mathbf{2 0 . 0 0 0}$, sobre Tráfico Ilícito de Estupefacientes y Sustancias Sicotrópicas, con el objeto de legalizar el autocultivo de cannabis para el consumo privado" ${ }^{93}$.

Éste último se refundirá con el proyecto que "Modifica el Código Sanitario y la ley $\mathrm{N}^{\circ}$ 20.00o, que Sanciona el Tráfico Ilícito de Estupefacientes y Sustancias Sicotrópicas, con el objeto de despenalizar el expendio y el autocultivo de cannabis con fines medicinales" 94 presentado por diputados de varios partidos ${ }^{95}$. Luego de ser aprobado en la Comisión de Salud, pasó a la Sala; entre sus medidas más destacadas se encontraba el permiso para que los mayores de edad cultivaran "seis plantas individualmente consideradas o de un total de un metro cuadrado en interior con luz artificial, además de la tenencia de un máximo de quinientos gramos de sumidades floridas cosechadas secas sin aditivos, en un mismo y único domicilio". Otra novedad era que definía como porte para consumo personal los 10 gramos de cannabis. Con 68 votos a favor, 39 en contra y 5 abstenciones el proyecto de ley fue aprobado el 7 de julio de 2015, sin embargo, regresó a la Comisión de Salud ya que fue objeto de indicaciones ${ }^{96}$.

90. PLAZA PÚBLICA CADEM (2014) pp. 8-9.

91. BOLETÍN 9.470-07 (2014).

92. PROYECTO DE RESOLUCIÓN N 123 (2014).

93. BOLETÍN 9471-11 (2014).

94. BOLETÍN 9496-11 (2014).

95. Partido Radical Social Demócrata, Partido Demócrata Cristiano, Partido Comunista de Chile, Partido Socialista de Chile, Partido Por la Democracia, Partido Liberal de Chile.

96. CÁMARA DE DIPUTADOS, 363a Legislatura, Sesión 43a (2015). 
El proceso comenzó su decadencia cuando en octubre se dieron a conocer las indicaciones del Poder Ejecutivo, a través de las cuales estipuló que el porte para consumo personal y próximo en el tiempo se supondrá "cuando se posea, transporte, guarde o porte cantidades iguales o inferiores a dos gramos de cualquier especie, subespecie o variedades vegetales del género cannabis", y tal circunstancia se entenderá también "cuando el número de especies de cannabis plantadas, sembradas, cultivadas o cosechadas, no exceda de una planta" (cursivas propias) ${ }^{97}$.

Estos proyectos tendientes a autorizar el autocultivo y el porte para consumo personal fueron concebibles porque el esquema cognitivo de la clase dirigente chilena respecto del uso de cannabis, de las personas que deciden consumir, así como el rol que ante esta conducta compete al Estado se quebró y otras ideas entraron a competir, aunque sin lograr la preponderancia. Si bien este quiebre puede relacionarse a muchos factores, quisiéramos destacar uno: en los diez años de vigencia de la ley 20.000 hubo un importante incremento del consumo de marihuana, lo cual también implica un mayor grado de aceptación social de la práctica. Esta trayectoria al alza se puede apreciar en el siguiente gráfico:

Gráfico 1: Prevalencia anual de uso de marihuana en población general.

Evoluciôn de la prevalencias $(\%)$ de consumo de marihuana. Chile, 1994-2014

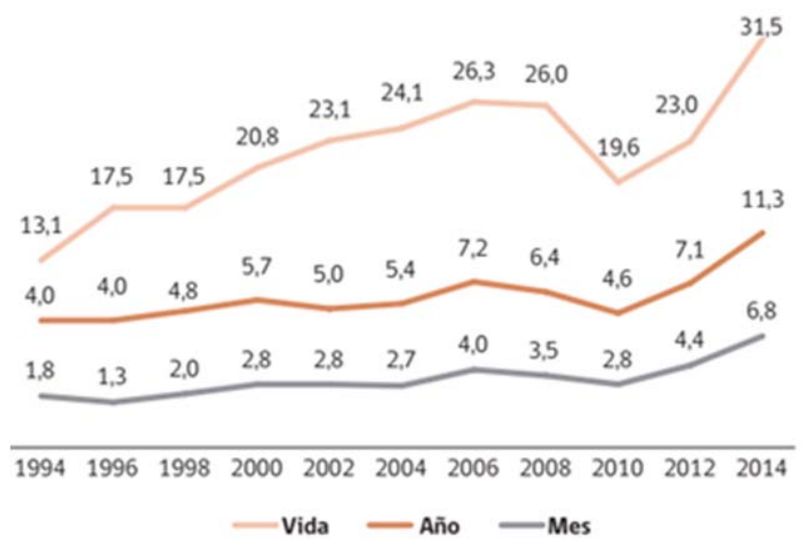

Fuente: SENDA (2015): Décimo Primer Estudio Nacional de Drogas en Población General de Chile 2014, 17.

97. OFICIO NO 997-363(2015). 
Podemos observar que para el año 2014 uno de cada tres chilenos había consumido al menos una vez en su vida marihuana. De modo que una parte de la dirigencia entendía que:

Hoy forma parte del escenario habitual de la vida de cientos de miles de chilenos que usan la marihuana como un elemento recreativo, religioso, terapéutico y de relajación. [...]. Esos miles de chilenos que usan la marihuana día a día como vehículo de distracción, también son seres humanos funcionales que trabajan, mantienen una familia, crían hijos y asumen las demás responsabilidades de toda persona mayor de edad, en tanto no caigan en una relación de adicción y dependencia (Independiente) ${ }^{98}$.

El concepto de libertad individual concentró muchas de las exposiciones del debate, en tal sentido se afirmó: "Debemos entender que, así como los chilenos deciden a quién eligen como Presidente de la República, también son capaces de tomar la decisión personal respecto de si quieren o no consumir marihuana" (Independiente, ex RN) ${ }^{99}$.

También en una parte de la dirigencia se resignificó la manera histórica de entender el problema, recordemos que los legisladores chilenos han entendido que los traficantes corrompen a los jóvenes con droga, esta idea no pierde vigencia, pero se entiende que al no permitir el autoabastecimiento de cannabis se los empuja a tal situación: “¿O acaso vamos a negar que los jóvenes que consumen marihuana y no la pueden cultivar, recurren a los microtraficantes para comprarla; que se ven obligados a acceder al mercado negro donde no solo compran marihuana de mala calidad, sino que se les abre la puerta a otro tipo de drogas duras, como la cocaína y la pasta base?" (Partido Comunista de Chile) ${ }^{100}$.

En relación a la conducta de porte, en la discusión de la Comisión de Salud se afirmó que: "[...] la distinción entre penalizar el uso o consumo de drogas con la posesión o tenencia de drogas para uso personal, es meramente académica, pues es imposible usar drogas sin poseerlas" ${ }^{101}$. Además, esta misma situación fue sostenida con datos en uno de los proyectos discutidos: "En nuestro país, del total de procedimientos realizados el año 2012, y en estadísticas elaboradas por la Subsecretaría de Prevención del Delito, 85.023 detenciones fueron por infracción a la Ley de Drogas, alcanzando el porte y consumo un total de $77.6 \%$ de los procedimientos" ${ }^{102}$.

98. CÁMARA DE DIPUTADOS, 363a Legislatura, Sesión 42a (2015) p. 47.

99. CÁMARA DE DIPUTADOS, 363a Legislatura, Sesión 43a (2015) p. 53.

100. CÁMARA DE DIPUTADOS, 363a Legislatura, Sesión 43a (2015) p. 46.

101. INFORME COMISIÓN DE SALUD (2015) p. 30.

102. BOLETÍN 9471-11 (2014). 
Sin embargo, el debate parlamentario mostró dos cuestiones: por un lado, la persistencia del esquema cognitivo normativo, y por otro, el cariz moral del asunto, en tanto los opositores esgrimieron que apoyaban el uso del cannabis terapéutico, pero no recreativo: "Sí es aceptable que la cannabis se use como medicamento. Pero aquí no hay que ser muy inteligente para darse cuenta de que permitir su cultivo personal y colectivo, claramente va a significar que un porcentaje muy pequeño se destine a fines medicinales, y uno muy alto, a fines no medicinales. Por lo tanto, como está planteado en los considerandos me parece un riesgo" (UDI) ${ }^{103}$.

Podemos observar que en esa parte de la dirigencia sigue operando el esquema cognitivo en torno al rol corruptor de menores por los narcotraficantes:

Lo que sí acepto es la utilización de la cannabis con fines medicinales. [...]. Por lo tanto, aprobaré esta iniciativa si el tema es aclarado y se puede votar por separado la utilización de marihuana con fines medicinales. Pero como me confirman que no se puede, pues se votará todo en un solo paquete, mi voto será en contra, porque no estoy dispuesto a que después me apunten con el dedo y digan que permití la existencia de traficantes en el país, que se dedican a corromper y vender drogas a nuestros niños $(\mathrm{RN})^{104}$.

Entonces, se dejó ver que, sobre la sustancia, quién la usa y el fin de su consumo, hay una concepción moral, es decir, hay un uso "bueno" y uno "malo":

Reitero, lamentablemente el proyecto de ley ha ido más allá de lo que se pensó en un principio. Por eso, hemos presentado algunas indicaciones destinadas a corregir ciertos aspectos que han transformado el proyecto en algo que va más allá del espíritu que sus propios autores tuvieron en un principio. La iniciativa tenía un fin muy loable, cual es destinar la cannabis para fines medicinales $(\mathrm{RN})^{105}$.

Este proceso quedó trunco cuando en octubre de 2015 se conocieron las indicaciones realizadas por el Poder Ejecutivo que propuso bajar las cantidades de plantas y de gramos en el porte, y tanto legisladores como sociedad civil dejaron de acompañar el proyecto. Por ejemplo, la diputada Karla Rubilar que era promotora del proyecto declaró:

103. CÁMARA DE DIPUTADOS, Sesión 74a, Legislatura 362a (2014) p. 62.

104. CÁMARA DE DIPUTADOS, Sesión 43a, Legislatura 363a (2015) p. 38.

105. CÁMARA DE DIPUTADOS, Sesión 42a, Legislatura 363a (2015) p. 38. 
Esto es un proyecto que realmente es un retroceso en materia de libertades, no respeta para nada el espíritu de los que presentamos este proyecto de ley. Es claramente prohibicionista, es claramente sancionatorio, ya la verdad es que uno no sabe si reír o llorar y lo único que puedo decir es que después de estas indicaciones, mejor cerremos por fuera porque no hay nada más que tramitar. Este proyecto tiene que quedarse hasta aquí porque la hoy ley 20.000 -sobre todo después del fallo de la Corte Suprema- es muchísimo mejor y muchísimo más respetuosa de las libertades que lo que está tratando de sacar el Ejecutivo ${ }^{106}$. No hay nada que hacer después de esto, este proyecto no se puede aprobar así, asique es preferible que el proyecto muera hoy ${ }^{107}$.

No obstante, la presidenta Michelle Bachelet emitió en diciembre el decreto 84 mediante el cual cambió la clasificación del cannabis en relación al uso terapéutico, a través de modificaciones a los Decretos 404 y 4.05 del Ministerio de Salud ${ }^{108}$. Como indicamos en el apartado teórico, el apoyo del ejecutivo en estas políticas es clave: si bien no podemos saber cuál era la postura de Michelle Bachelet, podemos deducir de sus acciones que el tema no era prioritario en su agenda de gobierno ${ }^{109}$. Es importante destacar que al realizar la investigación pudimos advertir que hubo otro tema al que la presidenta le puso todo su capital político y que justamente es otro asunto moral: la ley 21.030 que Regula la despenalización de la interrupción voluntaria del embarazo en tres causales ${ }^{110}$.

106. Rubilar se refería al fallo que dictó la Segunda Sala de la Corte Suprema, en junio de 2015, por el cual absolvió a la psicóloga Paulina González Céspedes del delito de cultivo de cannabis (CORTE SUPREMA 2015).

107. ADN (2015).

108. Decreto 84, de 2015.

109. Lo cual también fue advertido por los opositores a la ley: “[...] aun cuando el proyecto fue patrocinado y suscrito por parlamentarios del oficialismo, no contó y no cuenta hasta el momento con respaldo del Ejecutivo. De hecho, la señal sintomática de ello es la ausencia del Ejecutivo en la sesión de hoy y su ausencia permanente en todas las sesiones celebradas por la Comisión de Salud. En otras palabras, ellos no le 'prestaron ropa', no respaldaron esta iniciativa". CÁMARA DE DIPUTADOS, Sesión 42a, Legislatura 363a (2015) p. 29.

110. Ley 21.030, de 2017. 


\section{Recapitulación y aproximaciones finales}

En este artículo hicimos una caracterización socio-histórica de la política de drogas chilena y la analizamos a partir del marco teórico propuesto. Mostramos cómo el esquema cognitivo-normativo que se formó en la dirigencia chilena en los '70 -cuando el problema de las drogas entra en la agenda legislativa- persistió a lo largo del desarrollo de la política de drogas; sólo para mediados de los 2010 logró apenas quebrarse, pero no emergió un esquema nuevo que lograra predominar.

A modo de síntesis presentamos el esquema cognitivo-normativo respecto del problema de las drogas prevaleciente en la dirigencia chilena a través de sus tres principales dimensiones, para observar cómo se fue actualizando, pero conservando la idea inicial. Es decir, las figuras describen la invariabilidad de las ideas entendidas como esquemas cognitivo-normativos.

Figura 1. Esquema cognitivo-normativo predominante en la dirigencia chilena sobre las personas que usan sustancias ilícitas.

- Jóven víctima del lucro de los narcotraficantes y de la dominación cultural.

1973 Enfermo o desviado

1985 - Enfermo

1985

- Jóven corrompido por narcotraficantes y víctima de la crisis de valores sociales.

1995 Enfermo o desviado

- Jóven corrompido por narcotraficantes y víctima de la crisis de valores sociales.

2005 Enfermo o desviado

- Personas adultas, funcionales que deciden usar cannabis

Fuente: Elaboración propia. 
Figura 2. Esquema cognitivo-normativo predominante en la dirigencia chilena sobre la conducta de tenencia de sustancias ilícitas para uso personal.

1973

- Despenalización. Internación compulsiva o colaboración con la autoridad

1985

- Despenalización

1995

- Despenalización. Sanción al porte, el autocultivo y el uso en público

2000

- Despenalización. Sanción al porte, el autocultivo y el uso en público

- Autocultivo de 6 plantas y porte de 10 gramos

Fuente: Elaboración propia.

Figura 3. Esquema cognitivo-normativo predominante en la dirigencia chilena respecto del Estado como mediador entre la sustancia y los ciudadanos.
- Educación; tratamiento de recuperación; una medida educativa de colaboración
1973 con la autoridad

1985

- Educación; tratamiento de recuperación (en entidades privadas)

1995

- Campañas de prevención centradas en recomponer los valores

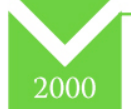

- Formación de los jóvenes que les permita decir que no, en forma libre y espontánea, cada vez que se les ofrezca droga

- Pleno respeto y observancia de los derechos y garantías fundamentales, debe regular y admitir el autocultivo

Fuente: Elaboración propia. 
A lo largo de este trabajo también hemos podido ver que las ideas que articulan el esquema cognitivo-normativo predominante acerca del problema de las drogas en la dirigencia chilena han sido desafiadas por otras ideas cada vez que se reformó la ley, no obstante, ninguna logró un quiebre que permitiese un cambio en la política respecto del porte de cannabis y el autocultivo, conductas que están descriminalizadas desde 1973 .

\section{Referencias bibliográficas}

ADN (2015): Gobierno disminuye cantidades de porte de marihuana en proyecto de despenalización. [Fecha de Consulta: 18 de agosto de 2020]. Disponible en: https:// www.adnradio.cl/nacional/2015/11/10/gobierno-disminuye-cantidades-de-portede-marihuana-en-proyecto-de-despenalizacion-2994570.html.

BÉLAND, Daniel (2019): How Ideas and Institutions Shape the Politics of Public Policy. Elements in Public Policy (Cambridge: Cambridge University Press).

CAMPBELL, John (2004): Institutional Change and Globalization (Princeton University Press).

ENGELI, Isabelle, GREEN-PEDERSEN, Christoffer y LARSEN, Lars Thorup (2012): Morality Politics in Western Europe: Parties, Agendas and Policy Choices (London, Palgrave Macmillan).

HEICHEL, Stephan, KNILL, Christoph y SCHMITT, Sophie (2013): "Public policy meets morality: conceptual and theoretical challenges in the analysis of morality policy change". En Journal of European Public Policy, vol. 2o, nº 3, pp. 318-334. DOI: $10.1080 / 13501763.2013 .761497$.

HURKA, Steffen, ADAM, Christian y KNILL, Christoph (2017): "Is Morality Policy Different? Testing Sectoral and Institutional Explanations of Policy Change". En Policy Studies Journal, vol. 45, nº. 4, pp. 688-712. DOI: 10.1111/psj.12153.

IBAÑEZ, Marcelo (2018): Un viaje fantástico: Breve historia de la marihuana en Chile y el mundo (Santiago de Chile, Grupo Planeta).

INGLEHART, Ronald (1971): “The Silent Revolution in Europe: Intergenerational Change in Post-Industrial Societies". En The American Political Science Review, vol. 65, nº. 4, pp. 991-1017. DOI: 10.2307/1953494.

JACOBS, Alan (2014): "Process tracing the effects of ideas". En Bennett, Andrew y Checkel, Jeffrey. Process Tracing: From Metaphor to Analytic Tool (Cambridge, Cambridge University Press), pp. 41-73. 
KNILL, Christoph (2013): "The study of morality policy: analytical implications from a public policy perspective". En Journal of European Public Policy, vol. 20, nº. 3, pp. 309-317. DOI: 10.1080/13501763.2013.761494.

LABIANO, Virginia (2020): “Estilos estatales de regulación de las drogas ilegales en Sudamérica". En Revista Mexicana de Ciencias Políticas y Sociales, vol. 65, nº. 240, pp. 89-118. ISSN 2448-492X. DOI: http://dx.doi.org/10.22201/fcpys.244849 2xe.2020.240.67073.

LABIANO, Virginia (2020): "La difusión de las politicas de cannabis medicinal en América Latina (2015-2017)”. En Redes. Revista de Estudios Sociales de la Ciencia y la Tecnología, vol. 26, $\mathrm{n}^{\circ}$. 50, pp. 147-179. ISSN 1851-7072. DOI: $10.48160 / 18517072$ re50.13.

LOWI, Theodore (1972): "Four Systems of Policy, Politics, and Choice". En Public Administration Review, vol. 32, nº. 4, pp. 298-310. DOI: 10.2307/974990.

MOONEY, Christopher (1999): “The Politics of Morality Policy: Symposium Editor's Introduction". En Policy Studies Journal, vol. 27, n . 4, pp. 675-68o. DOI: 10.1111/ j.1541-0072.1999.tbo1995.x.

MOONEY, Christopher y SCHULDT, Richard (2008): “Does morality policy exist? Testing a basic assumption". En Policy Studies Journal, vol. 36, n. 2, pp. 199-218. DOI: 10.1111/j.1541-0072.2008.00262.x.

PARSONS, Craig (2002): "Showing Ideas as Causes: The Origins of the European Union". En International Organization, vol. 56, $\mathrm{n}^{\circ}$. 1, pp. 47-84. DOI: 10.1162/o02081802753485133.

ORGANIZACIÓN DE LOS ESTADOS AMERICANOS (2013): El problema de las drogas en las Américas. Washington, D.C.: Secretaría General. [Fecha de Consulta: 13 de mayo de 2019]. Disponible en: http://www.oas.org/documents/spa/press/ Introduccion_e_Informe_Analitico.pdf.

PARSONS, Craig (2007): How to Map Arguments in Political Science (Oxford, Oxford University Press).

PLAZA PÚBLICA CADEM (2014): Especial legalización de la marihuana. Estudio $\mathrm{N}^{\circ}$ 31. Disponible en: https://plazapublica.cl/wp-content/uploads/archivos/EspecialLegalizaci\% $\mathrm{C}_{3} \% \mathrm{~B}_{3} \mathrm{n}$-de-la-Marihuana.pdf.

QUEIROLO, Rosario, ROSSEL, Cecilia, ÁLVAREZ, Eliana y REPETTO, Lorena (2019): "Why Uruguay legalized marijuana? The open window of public insecurity". En Addiction, vol. 114, n. 7, pp. 1313-1321. DOI: 10.1111/add.14523. 
REPETTO, Lorena (2014): "Regulación del cannabis: ¿un asunto de seguridad? Entrada y mantenimiento en agenda de un problema de politica pública". En Revista Uruguaya de Ciencia Política, vol. 23, nº. 1, pp. 119-141.

SCHMIDT, Vivien (2008): "Discursive Institutionalism: The Explanatory Power of Ideas and Discourse". En Annual Review of Political Science, vol. 11, n. 1, pp. 303326. DOI: 10.1146/annurev.polisci.11.060606.135342.

TATALOVICH, Raymond y DAYNES, Byron (1998): Moral controversies in American politics: cases in social regulatory policy (New York, M.E. Sharpe). Revised and expanded edition of Social regulatory policy, 1988.

VERGARA, Eduardo (2016): Chile y las drogas: una revisión sistemática mirando al futuro (Santiago de Chile, Cuarto Propio).

von HOFFMANN, Jonas (2019): "Commentary on Queirolo et al. (2019): The importance of 'top-down' support for processes of marijuana legalization". En Addiction, vol. 114, n'. 7, pp. 1322-1323. DOI: https://doi.org/10.1111/add.14581.

\section{Documentos y normas utilizadas}

Biblioteca del Congreso Nacional de Chile, s/f. Historia de la ley $\mathrm{N}^{\circ}$ 17.934. Reprime tráfico de Estupefacientes [en línea], [Fecha de Consulta: 7 de octubre de 2019]. Disponible en: https://obtienearchivo.bcn.cl/obtienearchivo?id=recursoslegal es/10221.3/28035/1/HL17934.pdf.

Biblioteca del Congreso Nacional de Chile, s/f. Historia de la Ley $\mathrm{N}^{\circ}$ 18.403. Sanciona el tráfico ilícito de drogas y estupefacientes y deroga la Ley $\mathrm{N}^{\circ}$ 17.934 [en línea], [Fecha de Consulta: 10 de octubre de 2019]. Disponible en: https://obtienearchivo. bcn.cl/obtienearchivo?id=recursoslegales/10221.3/35037/1/HLDto262.pdf.

Biblioteca del Congreso Nacional de Chile, s/f. Historia de la Ley No 19.366. Sanciona el tráfico ilícito de estupefacientes y sustancias sicotrópicas, dicta y modifica diversas disposiciones legales y deroga ley $\mathrm{N}^{\circ} \mathbf{1 8 . 4 0 3}$ [en línea], [Fecha de Consulta: 20 de noviembre de 2019]. Disponible en: https://www.bcn.cl/historiadelaley/nc/ historia-de-la-ley/6864/.

Biblioteca del Congreso Nacional de Chile, s/f. Historia de la Ley $\mathrm{N}^{\circ}$ 20.0oo. Sustituye la Ley $\mathrm{N}^{\circ}$ 19.366, que sanciona el tráfico ilícito de estupefacientes y sustancias sicotrópicas [en línea], [Fecha de Consulta: 14 de enero de 2020]. Disponible en: https://www.bcn.cl/historiadelaley/nc/historia-de-la-ley/5755/.

Boletín 3269-07. Legalización de cultivo de especies vegetales productoras de sustancias estupefacientes o sicotrópicas para consumo personal, 352a. Legislatura, Sesión 30a, 19 de enero de 2005. 
Boletín 3269-07. Moción del Honorable Senador Señor Ávila, por medio de la cual inicia un proyecto que modifica la Ley No 19.366 con el objeto de despenalizar la siembra, plantación, cultivo o cosecha de especies vegetales del género cannabis $u$ otras productoras de substancias estupefacientes o sicotrópicas destinadas al uso o consumo personal exclusivo y próximo en el tiempo, 349 Legislatura, Sesión 7a, 1 de julio de 2003.

Boletín 3812-07. Permite el autocultivo de especies vegetales del género cannabis con fines terapéuticos, 352a. Legislatura, Sesión 38a, 22 de marzo de 2005.

Boletín 9.470-07. Proyecto de ley, iniciado en moción de los Honorables Senadores señora Allende y señores De Urresti, Letelier, Montes y Rossi, que modifica la ley $\mathrm{N}^{\circ}$ 20.ooo con el objeto de despenalizar el auto cultivo, cosecha, porte o consumo, regulados a escala individual, de plantas vegetales del género cannabis, cuando esas conductas se funden en razones de índole personal, terapéutica o espiritual, 362a Legislatura, Sesión 34a, 23 de julio de 2014.

Boletín 9471-11. Modifica la ley $\mathrm{N}^{\circ}$ 20.00o, sobre Tráfico Ilícito de Estupefacientes y Sustancias Sicotrópicas, con el objeto de legalizar el autocultivo de cannabis para el consumo privado, 362a Legislatura, Sesión 50a, 24 de julio de 2014.

Boletín 9496-11. Modifica el Código Sanitario y la ley $\mathrm{N}^{\circ}$ 20.00o, que Sanciona el Tráfico Ilícito de Estupefacientes y Sustancias Sicotrópicas, con el objeto de despenalizar el expendio y el autocultivo de cannabis con fines medicinales, 362a Legislatura, Sesión 54a, 12 de agosto de 2014.

Boletín $\mathrm{N}^{\circ}$ 8.510-07. Proyecto de ley, iniciado en moción de los Honorables Senadores señores Lagos, Letelier y Rossi, que modifica la Ley que Sanciona el Tráfico Ilícito de Estupefacientes y Sustancias Sicotrópicas estableciendo una exención de responsabilidad penal para el cultivo y porte del género cannabis sativa, en los casos que indica, 36oa Legislatura, Sesión 40a, 8 de agosto de 2012.

Código Penal. Crímenes y Simples Delitos contra la Salud Pública. Santiago, noviembre 12 de 1874 [en línea], [Fecha de Consulta: 20 de enero de 2020]. Disponible en: https://www.leychile.cl/Navegar?idNorma=1984.

Comité evaluación de la ley de la Cámara de Diputados de Chile. Evaluación de la ley 20.00o, que sanciona el tráfico ilícito de estupefacientes y sustancias sicotrópicas, enero de 2014 .

Decreto 84. Modifica los Decretos Supremos No 404 y 405, ambos de 1983, Reglamento de Estupefacientes y Reglamento de Psicotrópicos, respectivamente, ambos del Ministerio de Salud, 7 de diciembre de 2015. 
Discurso del Presidente de la República de Chile, Dr. Salvador Allende Gossens en el acto de inauguración del año escolar 1971, 25 de julio de 1971. [Fecha de Consulta: 16 de enero de 2020]. Disponible en: http://www.lemondediplomatique.cl/ discurso-pronunciado-por-salvador-allende-el-25-de-julio-de-1971-la-educacion.

Informe de la Comisión Especial de Drogas sobre la aplicación y eficacia de los instrumentos legales que proporciona la ley No 19.366, que sanciona el tráfico ilícito de estupefacientes y sustancias psicotrópicas, relativos a la represión del consumo y tráfico de drogas y del lavado de dinero, 339a. Legislatura, Sesión 58a, 4 de mayo de 1999, pp. 142-163.

Informe de la Comisión Especial Investigadora del Problema de la Droga en Chile, 322a. Legislatura, Sesión 32a, 21 de agosto de 1991, pp. 3101-3171.

Legalización del autocultivo de cannabis para consumo privado y despenalización de su expendio y cultivo para fines medicinales. Primer Trámite Constitucional. Boletines Nos 9471-11 y 9496-11, 363a Legislatura, Sesión 42a, 2 de julio de 2015, pp. 25-51.

Legalización del autocultivo de cannabis para consumo privado y despenalización de su expendio y cultivo para fines medicinales. Primer Trámite Constitucional. Boletines Nos 9471-11 y 9496-11. Continuación, 363a Legislatura, Sesión 43a, 7 de julio de 2015, pp. 25-73.

Ley 17155 (11/o6/1969). Modifica Código Penal en lo relativo a delitos contra la salud pública y códigos de procedimiento penal y sanitario.

Ley 17934 (16/o5/1973). Reprime tráfico de estupefacientes.

Ley 18403 (04/03/1985). Sanciona el tráfico ilícito de drogas y estupefacientes y deroga la Ley $\mathrm{N}^{\circ} 17.934$.

Ley 19366 (30/o1/1995). Sanciona el tráfico ilícito de estupefacientes y sustancias sicotrópicas, dicta y modifica diversas disposiciones legales y deroga ley $\mathrm{N}^{\circ} 18.403$.

Ley 20000 (16/02/2005). Sustituye la Ley No 19.366, que sanciona el tráfico ilícito de estupefacientes y sustancias sicotrópicas.

Ley 21030 (23/o9/2017). Regula la despenalización de la interrupción voluntaria del embarazo en tres causales.

Ley $\mathrm{N}^{\circ} 20.502$ (21/02/2011). Crea el Ministerio del Interior y Seguridad Pública y el Servicio Nacional para la Prevención y Rehabilitación del Consumo de Drogas y Alcohol, y modifica diversos cuerpos legales. 
Oficio No 997-363. Formula indicaciones al proyecto de ley que modifica Código Sanitario y Ley $\mathrm{N}^{\circ} 20.000$, que sustituye la Ley No19.366, que sanciona el tráfico ilícito de estupefacientes y sustancias sicotrópicas, con el objeto de legalizar el autocultivo de cannabis para el consumo privado y despenalizar su expendio y cultivo para fines medicinales (Boletines $\mathrm{N}^{\circ}$ 9471-11 y 9496-11, Refundidos), 1 de octubre de 2015.

Proyecto de Acuerdo $\mathrm{N}^{\circ}$ 262. Reconstitución de la Comisión Especial de Drogas de la Cámara de Diputados, 330a Legislatura Extraordinaria, Sesión 71a, 18 de mayo de 1995.

Proyecto de acuerdo No 21. Reconstitución de la Comisión Especial de Drogas, 337a Legislatura, Sesión 17a., 6 de mayo de 1998.

Proyecto de Resolución $\mathrm{N}^{\circ} 123$, en virtud del cual se solicita a su excelencia la Presidenta de la República la regulación del uso medicinal de la cannabis sativa, 362a Legislatura, Sesión 74a, 1 de octubre de 2014, pp. 6o-65.

\section{Jurisprudencia}

Sala Segunda (Penal) de la Corte Suprema, 4 de junio de 2015 (Rol N $\left.{ }^{\circ} 4949-15\right)$. Acoge recurso de nulidad. Disponible en: https://www.pjud.cl/documents/396729/o/ CULTIVO+MARIHUANA+RITUAL.pdf/ 9 f 4 ac14a-464c-485c-9adbcc2b46721478 [Fecha de consulta: 19 de agosto de 2020]. 